БЕРЁЗКИНА Елена Юрьевна - аспирант Института социально-политических исследований Федерального научно-исследовательского социологического центра РАН (121069, Россия, г. Москва, Борисоглебский пер., 13, стр. 3; euproskurina@gmail.com)

\title{
ГЕНДЕРНАЯ ТЕМА В ДИСКУРСЕ ПРЕДСТАВИТЕЛЕЙ ИТАЛЬЯНСКИХ И РОССИЙСКИХ ПОЛИТИЧЕСКИХ ПАРТИЙ В СОЦИАЛЬНЫХ СЕТЯХ ВО ВРЕМЯ ИЗБИРАТЕЛЬНЫХ КАМПАНИЙ НАЦИОНАЛЬНОГО И НАДНАЦИОНАЛЬНОГО УРОВНЯ
}

\begin{abstract}
Аннотация. В статье рассматриваются особенности презентации гендерных тем в дискурсе лидеров политических партий современной Италии и России. На основе контент-анализа и дискурс-анализа высказываний политиков в Facebook в период избирательных кампаний в Европейский парламент и Государственную думу автор делает вывод о степени значимости гендерных тем для обществ России и Италии. Позиции политиков по гендерной тематике - маркирующий признак их политических позиций. Консервативная риторика преобладает в дискурсе лидеров правых политических партий. Вместе с тем проблемы равенства женщины и ее места в социально-экономической жизни страны наибольшее освещение получают в сообщениях политиков-женщин вне зависимости от их политической ориентации. Ключевые слова: политические партии, гендерное равенство, дискурс, выборы, Европейский парламент, Италия, парламентские выборы
\end{abstract}

Вступление. Тема гендерного равенства, гарантия равных прав и возможностей для всех категорий граждан - часть социальной политики современного демократического государства. Отражение таких вопросов, как финансовая поддержка семей с помощью социальных льгот, обеспечение доступа к работе (в т.ч. на должности с возможностью принятия решений) и равной оплаты труда, обеспечение безопасности, взгляды на репродуктивные права в дискурсе политиков в период проведения избирательной кампании - маркирующий элемент политической ориентации акторов.

Несмотря на степень доступности Интернета и распространенность социальных сетей в России, эти площадки до сих пор не стали значимыми коммуникационными каналами для российских политиков при общении с аудиторией в период проведения избирательных кампаний. В Италии же, наоборот, социальные сети с 2013 г. играют заметную роль в коммуникации политиков и их избирателей. Анализ политического дискурса политиков из страны - партнера РФ (в области политического диалога лидеров, экономики и культуры) в ЕС может способствовать корректировке коммуникационных стратегий россиян, увеличению роли взаимодействия с избирателями и его эффективности на таких площадках, как страницы в социальных сетях.

В качестве иллюстрирующих примеров были выбраны данные по последним большим избирательным циклам: выборы депутатов от Италии в Европейский парламент в 2019 г. и выборы в Государственную думу 2021 г. в России. Подобное сравнение не позволяет сделать полноценные выводы в силу того, что это выборы разного уровня, масштаба и времени. Но более длительный анализ 
показывает, что характер дискурса по женским вопросам и вопросам равенства стабилен и не склонен к значительным изменениям в течение нескольких лет.

Высший орган исполнительной власти Европейского союза - Европейская комиссия (European Commission) ставит задачи по обеспечению экономической независимости женщин и мужчин, сокращению разрыва в оплате труда, защите женщин от насилия ${ }^{1}$. В составе правительства РФ также действует ряд комиссий и советов, в т.ч. и Координационный совет по реализации Национальной стратегии действий в интересах женщин на 2017-2022 гг., в задачи которого входит совершенствование политики в сфере улучшения положения женщин.

Таким образом, Италия как одна из стран ЕС должна стремиться к соответствию реальности и европейским идеалам равенства. Россия также ставит перед собой задачу улучшения положения женщин. Однако, согласно данным доклада «Гендерный разрыв 2021» (Global Gender Gap Report 2021) Всемирного экономического форума (ВЭФ), Италия находится на 63-м месте из 156, а Россия - на 81-м². Таким образом, тема гендерного равенства, и особенно вопросы по обеспечению женщин не только работой и равной с мужчинами зарплатой, но и социальными гарантиями в период беременности, родов и ухода за детьми в первый год жизни, должна была стать одной из основных во время избирательной кампании в Европейский парламент и теоретически должна была быть отражена в избирательной кампании в Государственную думу в 2021 г.

Цель и методы исследования. Цель данной работы - проанализировать высказывания итальянских и российских политиков в социальных сетях на гендерные темы, включая такие вопросы, как социальные гарантии и права традиционных семей, социальные гарантии и права женщин, права меньшинств, а также сделать вывод о значимости гендерных тем.

Метод исследования - сочетание контент-анализа сообщений представителей итальянских политических партий в Facebook и дискурс-анализа сообщений.

Контент-анализ подходит для качественно-количественного анализа документов, в данной работе - сообщений в социальных сетях, и выявления факторов и тенденций относительно гендерных тем в обществе. Для усиления анализа социального контекста используется метод дискурс-анализа, т.е. учитываются индивидуальные и социальные особенности источников сообщений, а также их цели и установки. Такое понимание дискурса соответствует определению Т.А. ван Дейка: «...дискурс - это речевой поток, язык в его постоянном движении, вбирающий в себя все многообразие исторической эпохи, индивидуальных и социальных особенностей как коммуниканта, так и коммуникативной ситуации, в которой происходит общение» [Ван Дейк 1989], а также лингвистов В.В. Петрова и Ю.Н. Караулова, которые определяют дискурс как «сложное коммуникативное явление, включающее, кроме текста, еще и экстралингвистические факторы (знания о мире, мнения, установки, цели адресанта), необходимые для понимания текста» [Петров, Караулов 1989].

В качестве материала для исследования были выбраны публикации итальянских политиков в социальной сети Facebook, сделанные в период с 1 марта 2019 г. по 25 мая 2019 г. Выбор временных рамок обусловлен тем, что список кандидатов должен был быть зарегистрирован не позже 17 мая, а избиратель-

\footnotetext{
1 Gender equality, European Commission, Justice and fundamental rights. URL: https:// ec.europa.eu/info/policies/justice-and-fundamental-rights/gender-equality_en (accessed 12.01.2022).

2 The Global Gender Gap Index 2021 rankings. URL: https://www3.weforum.org/docs/WEF GGGR_2021.pdf (accessed 12.01.2022).
} 
ная кампания проходила с 18 апреля по 25 мая 2019 г. (26.05.2019 - день выборов в Европейский аарламент в Италии).

Вторую часть эмпирической базы исследования составили сообщения российских политиков в Facebook, сделанные в период с 18 июня по 19 сентября 2021 г. - со старта избирательной кампании до последнего дня голосования.

Выбор платформы Facebook объясняется тем, что абсолютное большинство политиков, представляющих парламентские партии, зарегистрированы в Facebook и используют эту площадку в качестве одного из каналов коммуникации с избирателями. Преимущество сообщений в социальных сетях перед сообщениями и интервью в СМИ в том, что они представляют собой цельные сообщения из первоисточника. Недостатком исследования сообщений политиков в социальных сетях является сложность подсчета общего числа сообщений и разная вовлеченность персоналий в ведение страниц в социальных сетях.

Согласно данным официального сайта Европарламента, в 2019 г. от Италии в выборах участвовали 9 крупных партий, из которых в парламент прошли 6: «Лига Сальвини в премьеры» (Lega Salvini Premier) - 28 мест, Демократическая партия (Partito Democratico (con Siamo Europei) - 19 мест, «Движение пяти звезд» (Movimento Cinque Stelle) - 14 мест, «Вперед, Италия» (Forza Italia) 6 мест, «Братья Италии» (Fratelli d'Italia) - 5 мест, «Южнотирольская народная партия» (Südtiroler Volkspartei) - 6 мест 11 .

Критерием для отбора представителей политических партий стали итальянский язык сообщений, занимаемая должность в руководящем аппарате партии и возможность давать комментарии от лица политической партии на момент проведения избирательной кампании в Европейский парламент в 2019 г. Таким образом, в выборку не попали немецкоговорящие представители «Южнотирольской народной партии».

Таким образом, анализировались сообщения в Facebook следующих 12 персон от 8 партий: Никола Дзингаретти (Nicola Zingaretti) и Паолы Де Микели (Paola De Micheli) - Демократическая партия, Никола Фратоианни (Nicola Fratoianni) - коалиция «Левые», Сильвио Берлускони (Silvio Berlusconi) и Антонио Таджани (Antonio Tajani) - «Вперед, Италия», Луиджи Ди Майо (Luigi Di Maio) и Беппе Грилло (Beppe Grillo) - «Движение пяти звезд», Маттео Сальвини (Matteo Salvini) - «Лига Сальвини в премьеры», Джорджиа Мелони (Giorgia Meloni) и Карло Фиданца (Carlo Fidanza) - «Братья Италии», Маттео Бадиали (Matteo Badiali) - «Федерация зеленых», Джанфранко Спадаччиа (Gianfranco Spadaccia) - «+Европа».

Российская часть исследования - представители парламентских партий (лидеры списков и председатели политических партий) Государственной думы VIII созыва: «Единая Россия» (Д.А. Медведев, С.К. Шойгу, С.В. Лавров, Д.Н. Проценко, Е.В. Шмелева, А.Ю. Кузнецова), КПРФ (Г.А. Зюганов), «Справедливая Россия - Патриоты - За правду» (С.М. Миронов, Е.Н. Прилепин [Захар Прилепин]), ЛДПР (В.В. Жириновский), «Новые люди» (А.Г. Нечаев, С.В. Авксентьева).

Из-за того, что представленные политические партии имеют неодинаковую структуру управления и порядок наделения полномочиями своих представителей выражать точку зрения партии, число проанализированных высказываний представителей от каждой партии различается.

Количественные результаты исследования. Для оценки степени значимости гендерных тем в дискурсе итальянских и российских политиков были про-

1 Risultati delle elezioni europee del 2019. Доступ: https://www.europarl.europa.eu/electionresults-2019/it/risultati-nazionali/italia/2019-2024/ (проверено 12.01.2022). 
анализированы сообщения на страницах в Facebook, при этом комментарии политиков под их сообщениями или на других страницах не учитывались. В указанный период публикации разных итальянских политиков производились неравномерно. Наиболее активными оказались Паола Де Микели, Сильвио Берлускони, Луиджи Ди Майо, Беппе Грилло, Маттео Сальвини и Джорджиа Мелони. В среднем в день публиковалось от 1 до 3 сообщений на разные темы, у остальных публикации выходили реже. В избирательную кампанию 2021 г. публикации российских политиков также велись неравномерно. Наиболее активными оказались А.Ю. Кузнецова, В.В. Жириновский и С.В. Авксентьева.

Поиск сообщений велся по 3 темам: социальные гарантии и права традиционных семей, социальные гарантии и права женщин, права меньшинств. В каждой из этих тем поиск велся по ключевым словам.

1-я группа «Социальные гарантии и права традиционных семей»: родительство, усыновление, алименты, традиционные семейные ценности, брак, развод, брачный возраст, отцовство, материнство, субсидии для молодых семей, многодетные семьи, пособие по уходу за ребенком, детский сад, семья, женщина, мужчина, права родителей при приеме на работу, социальная поддержка родителей-одиночек.

2-я группа «Социальные гарантии и права женщин»: беременность, аборт, равные права для мужчин и женщин, насилие в отношении женщин, порнография, женщина, пособие при рождении и уходе за ребенком, отпуск по уходу за ребенком, трудовые гарантии женщин, работающие женщины, брачный возраст, трудовые права беременных и молодых матерей.

3-я группа «Права меньшинств»: ЛГБТ, родительство, усыновление, семья, брак, развод, насилие в отношении меньшинств.

Отсутствие сообщений на гендерные темы на страницах Маттео Бадиали и Джанфранко Спадаччиа может объясняться тем, что социальные сети не воспринимаются ими как релевантный коммуникационный канал с избирателями, а вопросы гендерного равенства не являются приоритетными для освещения.

Наименее редко встречающаяся в сообщениях итальянских политиков тема о правах меньшинств. 6 человек из 12 избегают упоминаний этой темы. Не все упоминания о правах меньшинств имеют положительную окраску. Маттео Сальвини, Джорджиа Мелони говорят о правах меньшинств в контексте критики темы суррогатного материнства и усыновления. Высказывания других политиков о правах меньшинств более сдержанны и нейтральны. Лидеры «Движения пяти звезд» акцентируют внимание на социально-экономических проблемах, а именно на проблеме безработицы и низких зарплат, и предлагают финансовую поддержку семей без разделения на традиционные и однополые, подразумевая под семьями людей, живущих в браке (недоступно для однополых пар) и в гражданском союзе 1.

О проблеме социальной поддержки женщин и обеспечении их равными правами говорят все политики, кроме Маттео Бадиали и Джанфранко Спадаччиа. Все упоминания можно разделить на несколько групп по контексту, в котором это происходит: экономические проблемы и включенность женщин в экономику (создание рабочих мест и достижение равной с мужчинами оплаты труда), дети и их матери (финансовая поддержка матерей, повышение доступности детских садов, продление отпуска по уходу за ребенком), а также преступления

1 Legge 20 maggio 2016, n. 76. - Gazzetta ufficiale. Доступ: https://www.gazzettaufficiale.it/eli/ $\mathrm{id} / 2016 / 05 / 21 / 16 \mathrm{G} 00082 / \mathrm{sg}$ (проверено 12.01.2022). 
Таблииа 1

Количественные результаты исследования высказываний итальянских политиков

\begin{tabular}{|c|c|c|c|}
\hline ФИО & $\begin{array}{c}\text { Социальные } \\
\text { гарантии и права } \\
\text { традиционных семей }\end{array}$ & $\begin{array}{c}\text { Социальные } \\
\text { гарантии и права } \\
\text { женщин }\end{array}$ & $\begin{array}{c}\text { Социальные } \\
\text { гарантии и права } \\
\text { менышинств }\end{array}$ \\
\hline $\begin{array}{l}\text { Никола Дзингаретти } \\
\text { (Nicola Zingaretti) }\end{array}$ & 3 & 2 & 0 \\
\hline $\begin{array}{l}\text { Паола Де Микели } \\
\text { (Paola De Micheli) }\end{array}$ & 16 & 26 & 0 \\
\hline $\begin{array}{l}\text { Никола Фратоианни } \\
\text { (Nicola Fratoianni) }\end{array}$ & 11 & 20 & 3 \\
\hline $\begin{array}{l}\text { Сильвио Берлускони } \\
\text { (Silvio Berlusconi) }\end{array}$ & 12 & 10 & 0 \\
\hline $\begin{array}{l}\text { Антонио Таджани } \\
\text { (Antonio Tajani) }\end{array}$ & 5 & 2 & 0 \\
\hline $\begin{array}{l}\text { Луиджи Ди Майо } \\
\text { (Luigi Di Maio) }\end{array}$ & 8 & 9 & 5 \\
\hline $\begin{array}{l}\text { Беппе Грилло } \\
\text { (Beppe Grillo) }\end{array}$ & 5 & 9 & 2 \\
\hline $\begin{array}{l}\text { Маттео Сальвини } \\
\text { (Matteo Salvini) }\end{array}$ & 21 & 14 & 2 \\
\hline $\begin{array}{l}\text { Джорджиа Мелони } \\
\text { (Giorgia Meloni) }\end{array}$ & 15 & 26 & 5 \\
\hline $\begin{array}{l}\text { Карло Фиданца } \\
\text { (Carlo Fidanza) }\end{array}$ & 6 & 2 & 2 \\
\hline $\begin{array}{l}\text { Маттео Бадиали } \\
\text { (Matteo Badiali) }\end{array}$ & 0 & 0 & 0 \\
\hline $\begin{array}{l}\text { Джанфранко Спадаччиа } \\
\text { (Gianfranco Spadaccia) }\end{array}$ & 0 & 0 & 0 \\
\hline
\end{tabular}

в отношении женщин и детей (инфантицид, феминицид, распространение порнографии) и неравноправие в других странах и культурах (исламской).

Особенностью освешения женских проблем является то, что преобладающее число сообщений создано политиками-женщинами, среднее число упоминаний в несколько раз (2-10) превышает число упоминаний со стороны политиков-мужчин. Сравнение показателей среди мужчин говорит о том, что представители правых партий («Лига Сальвини в премьеры» и «Вперед, Италия») говорят о правах женщин чаще, чем представители левоцентристских партий и «Движения пяти звезд». Сильвио Берлускони больше пишет об экономической поддержке женщин, а Маттео Сальвини сочетает в своих сообщениях темы равноправия и антиисламизма (одна из ключевых позиций его партии).

Тема семьи встречается в сообщениях итальянских политиков чаще других гендерных тем. Это связано с тем, что она лучше всего подходит для сообщения позиций политических партий по социально-экономическим вопросам, которые включают в себя создание рабочих мест и борьбу с безработицей, увеличение минимальной оплаты труда, налоговые реформы и поддержку среднего и малого бизнеса, финансовую поддержку экономически неблагополучных категорий граждан и стимуляцию рождаемости.

В целом, тон сообщений политиков по теме поддержки семей похож, здесь 
Таблииа 2

Количественные результаты исследования высказываний российских политиков

\begin{tabular}{|l|c|c|c|}
\hline \multicolumn{1}{|c|}{ ФИо } & $\begin{array}{c}\text { Социальные } \\
\text { гарантии и права } \\
\text { традиционыс семей }\end{array}$ & $\begin{array}{c}\text { Социальные } \\
\text { гантии и права } \\
\text { женщин }\end{array}$ & $\begin{array}{c}\text { Социальные } \\
\text { гарантии и права } \\
\text { меньшинств }\end{array}$ \\
\hline Д.А. Медведев & 4 & 1 & 0 \\
\hline С.К. Шойгу & - & - & - \\
\hline С.В. Лавров & - & - & 0 \\
\hline Д.Н. Проценко & 0 & 0 & - \\
\hline Е.В. Шмелева & - & - & 0 \\
\hline А.Ю. Кузнецова & 60 & 26 & 0 \\
\hline Г.А. Зюганов & 0 & 1 & 2 \\
\hline С.М. Миронов & 0 & 0 & 0 \\
\hline $\begin{array}{l}\text { Е.Н. Прилепин } \\
\text { (Захар Прилепин) }\end{array}$ & 10 & 1 & - \\
\hline В.В. Жириновский & 7 & 0 & 0 \\
\hline А.Г. Нечаев & - & - & 0 \\
\hline С.В. Авксентьева & 0 & 0 & \\
\hline
\end{tabular}

не наблюдаются категоричные различия. Политики выступают за расширение программ поддержки семей как напрямую - с помощью пособий, - так и с помощью экономического развития итальянского общества в целом.

Результаты анализа сообщений российских политиков указывают на то, что социальные сети играют меньшее значение в их коммуникационной стратегии, несмотря на то, что российские выборы проходили на 2 года позже, а число пользователей социальных сетей в России - 67,8\% населения (в Италии этот показатель составляет $57,6 \%)^{1}$. Из 12 политиков 4 не имеют официальной страницы в Facebook, еще двое (Д.Н. Проценко и Г.А. Зюганов) ведут страницы неактивно.

Если итальянские политики охватывают своими сообщениями различные темы, актуальные в обществе, то российские придерживаются ограниченного набора тем. В случае с «Единой Россией» это можно оправдать тем, что лидеры избирательного списка являются экспертами в определенных областях (Д.Н. Проценко - борьба с COVID-19, А.Ю. Кузнецова - защита материнства и детства). Другие политики (В.В. Жириновский, Е.Н. Прилепин) выбирают темы публикаций в основном исходя из своих личных интересов, а не задач партии или новостной повестки.

В целом, социальная политика и положение женщин не входят в основные темы сообщений российских политиков. В отличие от Италии, женщиныполитики не акцентируют внимание на женском вопросе. С.В. Авксентьева не пишет на эту тему, Е.В. Шмелева отсутствует в Facebook. Единственное исклю-

\footnotetext{
1 Аудитория социальных сетей и мессенджеров в 2021 году. - SkillFactory. Доступ: https:// blog.skillfactory.ru/auditoriya-soczialnyh-setej-i-messendzherov-v-2021-godu/ (проверено 12.01.2022); Statista: Number of social network users in Italy from 2017 to 2025. URL: https://www.statista.com/statistics/568968/predicted-number-of-social-network-users-in-italy/ (accessed 12.01.2022).
} 
чение - страница А.Ю. Кузнецовой (60 сообщений посвящены социальным гарантиям семей, 26 - социальным гарантиям женщин).

Bыводы. Гендерные темы находят отражение в сообщениях и выступлениях политических лидеров исследуемых партий обеих стран.

Итальянские политические лидеры стремятся на живых примерах и случаях из жизни в стране и мире продемонстрировать свои позиции по социальноэкономическим вопросам. Популярен такой тип сообщения, как комментарий новости или происшествия, часто имеющий яркую эмоциональную окраску. Другие способы выражения идей более стандартны и официальны - это поздравления и официальные речи, приуроченные к знаменательным событиям или значимым итальянским праздникам, а также традиционные для устных выступлений и политической рекламы аргументированные призывы голосовать.

Чем старше представитель политической партии, тем чаще он прибегает к более традиционным текстам сообщений. Более молодые политики предпочитают выражать свои идеи больше с помощью комментариев к новостям.

Тема прав ЛГБТ-сообщества для итальянских партий и политиков является маркером их принадлежности к правоцентристским и левоцентристским политическим движениям. Игнорирование этой темы присуще крупной Демократической партии, которая стремится искать поддержку у широких слоев избирателей, а также «Вперед, Италия», которая также не стремится высказывать радикальные идеи.

Тема прав женщин и социальных гарантий для них чаще используется политиками-женщинами: число сообщений на их страницах в Facebook в несколько раз выше, чем упоминаний на страницах мужчин.

Итальянское общество достаточно традиционно в вопросах семьи, материнства и прав женщин. Для страны актуален разрыв в оплате труда женщин и мужчин, большой процент женщин не включены в экономическую жизнь и не работают, возможно, из-за наличия маленьких детей. С другой стороны, существует проблема низкой рождаемости, которую связывают в т.ч. и с экономической нестабильностью и низкими доходами, поэтому во все программы включены меры экономической поддержки семей с детьми.

Российские политики более консервативны в ведении своих страниц в социальных сетях. В меньшей степени выражаются позиции политика по социальным вопросам через комментарии к публикациям в СМИ (исключения: А.Ю. Кузнецова и Е.Н. Прилепин). Социальная политика и права женщин - второстепенные вопросы: акцент делается на экономике или «экспертной» теме политика. Выбор «экспертной» темы зависит от должности или личных предпочтений политика, а не от его половой принадлежности (в отличие от Италии). Особенностью российских политиков является то, что их сообщения в социальных сетях по социальной тематике не позволяют определить их политическую ориентацию.

Сравнивая активность политиков Италии и России в социальных сетях, можно отметить, что итальянцы более свободно владеют инструментами прямой коммуникации с избирателем, лучше понимают возможности эмоционального воздействия на аудиторию с помощью текстов и охватывают более широкий пул проблем и вопросов, которые могут привлечь избирателей, чем российские политики. Пример итальянских коллег мог бы стать для российских политиков пособием по взаимодействию с избирателями в цифровой среде. 


\section{Список литературы}

Ван Дейк Т.А. 1989. Язык. Познание. Коммуникация. М.: Прогресс. 310 с.

Петров В.В., Караулов Ю.Н. 1989. Вступительная статья. - Ван Дейк Т.А. Язык. Познание. Коммуникация. М.: Прогресс. С. 5-11.

BEREZKINA Elena Yur'evna, postgraduate student at the Institute for Social and Political Studies, Russian Academy of Sciences - Branch of the Federal Center of Theoretical and Applied Sociology, Russian Academy of Sciences (bld. 3, 13 Borisoglebsky Lane, Moscow, Russia, 121069; euproskurina@gmail.com)

\section{THE COVERAGE OF GENDER RELATED THEMES IN THE DISCOURSE OF THE ITALIAN AND RUSSIAN POLITICIANS ON SOCIAL MEDIA DURING THE NATIONAL AND SUPRANATIONAL LEVELS OF ELECTION CAMPAIGNS}

\footnotetext{
Abstract. The article examines how gender-related topics are covered in the discourse of the Italian and Russian politicians. The author uses a synthesis of content analysis and discourse analysis of the statements of politicians on the social media during the election campaign for the European Parliament and the State Duma as a methodology of the study and uses the results of the analysis to explain how important gender-related topics are for the modern Italian and Russian society. Both the Italian and Russian politicians choose Facebook as key social media. According to the findings of the study, a gender position is a determining feature of a politician, which helps to define their political position (left wing, right wing or center). A conservative rhetoric prevails in the discourse of right-wing political leaders. In addition, women politicians, regardless of their political orientation, better cover the problems of women equality and their place in the socio-economic life.
} Keywords: political parties, gender equality, discourse, elections, European Parliament, Italy, populism 